\title{
Adsorption of Saliva Related Protein on Denture Materials: An X-Ray Photoelectron Spectroscopy and Quartz Crystal Microbalance Study
}

\author{
Akiko Miyake, ${ }^{1}$ Satoshi Komasa, ${ }^{1}$ Yoshiya Hashimoto, ${ }^{2}$ Yutaka Komasa, ${ }^{3}$ and Joji Okazaki ${ }^{1}$ \\ ${ }^{1}$ Department of Removal Prosthodontics and Occlusion, Osaka Dental University, 8-1 Kuzuhahanazonocho, Hirakata, \\ Osaka 573-1121, Japan \\ ${ }^{2}$ Department of Biomaterials, Osaka Dental University, 8-1 Kuzuhahanazonocho, Hirakata, Osaka 573-1121, Japan \\ ${ }^{3}$ Department of Geriatric Dentistry, Osaka Dental University, 8-1 Kuzuhahanazonocho, Hirakata, Osaka 573-1121, Japan
}

Correspondence should be addressed to Akiko Miyake; miyake-a@cc.osaka-dent.ac.jp

Received 30 September 2015; Accepted 22 December 2015

Academic Editor: Ying Li

Copyright (C) 2016 Akiko Miyake et al. This is an open access article distributed under the Creative Commons Attribution License, which permits unrestricted use, distribution, and reproduction in any medium, provided the original work is properly cited.

\begin{abstract}
The aim of this study was to evaluate the difference in the adsorption behavior of different types of bovine salivary proteins on the PMMA and Ti QCM sensors are fabricated by spin-coating and sputtering onto bare QCM sensors by using QCM and Xray photoelectron spectroscopy (XPS). SPM, XPS, and contact angle investigations were carried out to determine the chemical composition and surface wettability of the QCM surface. We discuss the quality of each sensor and evaluate the potential of the highfrequency QCM sensors by investigating the binding between the QCM sensor and the proteins albumin and mucin (a salivaryrelated protein). The SPM image showed a relatively homogeneous surface with nano-order roughness. The XPS survey spectra of the thin films coated on the sensors were similar to the binding energy of the characteristic spectra of PMMA and Ti. Additionally, the amount of salivary-related protein on the PMMA QCM sensor was higher than those on the Ti and Au QCM sensors. The difference of protein adsorption is proposed to be related to the wettability of each material. The PMMA and Ti QCM sensors are useful tools to study the adsorption and desorption of albumin and mucin on denture surfaces.
\end{abstract}

\section{Introduction}

The initial adhesion of microorganisms to clinically used dental biomaterials is influenced by physicochemical parameters, such as preadsorption of salivary proteins, and the formation of biofilms begins with the adhesion of microorganisms [1]. The presence of biofilms is thought to affect the ability of microorganisms to adsorb and accumulate on the surfaces of denture materials. Thus, it is likely that bacterial adhesion may also be affected, resulting in a greater risk of infection of the denture materials [2]. Many common materials, such as polymers and metal alloys, are currently used in dentures. Importantly, it is considered that microorganisms are easily adhered to polymer materials; thus, the quantitative investigation of the salivary protein adsorption to denture materials is necessary.
Denture cleanliness is essential to prevent the accumulation of microorganisms owing to its deleterious effects on the mucosa. There are a large number of solutions, pastes, and powders available for cleaning dentures with a variety of claims for their relative efficacies [3]. Chemical solution methods have the advantage of being simple to use. Thus, a quartz crystal microbalance (QCM) sensor device is needed to measure the cleaning ability of the chemical denture cleaner for each denture material.

A QCM is a highly sensitive and practical device for in situ monitoring of protein adsorption [4]. A QCMbased sensor consists of a quartz crystal and a sensing material. A $27 \mathrm{MHz}$ QCM is capable of measuring the mass in aqueous solutions with an extremely high sensitivity, and the resonance frequency has been shown to decrease linearly with increasing mass on the QCM electrode at the nanogram 
level $[5,6]$. QCM sensors have been fabricated by coating a thin film of a biomaterial on the gold electrode of the quartz crystal [7-10]. Previously, we fabricated poly(methyl methacrylate) (PMMA) and titanium (Ti) QCM sensors by the spin-coating and sputtering methods, respectively, to investigate the adsorption of salivary-related proteins on the denture surface $[7,8,11]$. However, the observation of a thick and nonuniform film on the gold electrode of the quartz crystal was a drawback. Hence, the fabrication of an ultrathin film is necessary for a QCM sensor.

PMMA, Au, and Ti have been used as denture materials owing to their biological safety [12-14], and QCM sensor devices that mimic the surface composition of each material will be required. In this study, the spin-coating and sputtering conditions for the fabrication of PMMA and Ti QCM sensors were improved to increase the repeatability and sensitivity. The differences in adsorption behavior of different types of bovine salivary proteins to these sensors were investigated by $\mathrm{X}$-ray photoelectron spectroscopy (XPS).

\section{Materials and Methods}

2.1. Sample Preparation. To prepare PMMA-coated sensors, the bare QCM sensors were first cleaned with Piranha solution (sulfuric acid: $30 \%$ hydrogen peroxide $=7: 3 \mathrm{v} / \mathrm{v}$ ). A $0.1 \mathrm{~g} / \mathrm{mL}$ solution of PMMA in ethyl acetate solution was used to coat the PMMA thin film onto the gold electrode of the quartz crystal at a spinning rate of 3,000 rpm for a period of $15 \mathrm{~s}$ in a spin-coater (SC4001, Aiden, Hyogo, Japan). The PMMA QCM sensor was turned on for $24 \mathrm{~h}$ at room temperature.

To prepare titanium QCM sensors as target materials, $\mathrm{Ti}$ discs with a diameter of 4 inches were used. These thin films were deposited on the gold electrode of the QCM sensors using direct current (DC) for the Ti target magnetron sputtering. The distance between the target and the substrate was $50 \mathrm{~mm}$. The sputtering chamber was evacuated to below $7 \times$ $10^{-4} \mathrm{~Pa}$ using an oil-diffusion pump. The sputtering gas used was $\mathrm{Ar}$ gas. The sputtering pressure was maintained at $0.2 \mathrm{~Pa}$ for the Ti target using a mass flow controller. The discharge power of the Ti target was $200 \mathrm{~W}$. The target was presputtered for $10 \mathrm{~min}$. The thickness of the Ti layer was $50 \mathrm{~nm}$.

2.2. Characterization of Materials. The surface topology and the roughness of the PMMA, the Ti, and bare QCM sensors were evaluated over a surface area of $1.0 \times 1.0 \mu \mathrm{m}$ by scanning probe microscopy (SPM-9600, Shimadzu, Kyoto, Japan).

The chemical compositions of the coating on the QCM sensors were analyzed by XPS on an AXIS Ultra DLD spectrometer (Kratos Instruments, Manchester, UK) equipped with a monochromated $\mathrm{Al} K_{\alpha} \mathrm{X}$-ray source $(h \nu=1486.6 \mathrm{eV})$ operated at $75 \mathrm{~W}$. High-resolution spectra were recorded at pass energies of $20 \mathrm{eV}$. Measurements were performed at a takeoff angle of $90^{\circ}$. All spectra were corrected using the signal of Cls at $285.0 \mathrm{eV}$ as an internal reference. The collected spectra were deconvoluted with a Gaussian-Lorentzian approximation, after Shirley background subtraction, using Vision 2 software (Kratos Instruments).
2.3. Contact Angle Measurements. The contact angle of the QCM sensor surface with respect to double-distilled water was measured using a drop shape analysis system (DSA 10 Mk2; KRÜSS, Hamburg, Germany). The contact angle is a simple measure of the surface energy and the hydrophilic nature of a surface. The mean and standard deviation were calculated for measurements taken at three different locations on each sample.

2.4. Salivary Proteins. Bovine serum albumin (BSA; Wako Pure Chemical Industries Ltd., Osaka, Japan) and bovine submaxillary gland mucin (BSM; Sigma-Aldrich Inc., Tokyo, Japan) were used to mimic human salivary proteins. BSA is a well-characterized protein with a molecular weight of $6.9 \times$ $10^{4}$, a size of $11.6 \times 2.7 \times 2.7 \mathrm{~nm}$, and an isoelectric point of $4.7-$ 4.9 [15]. BSM belongs to a glycoprotein class characterized mainly by a molecular weight of $1.6 \times 10^{6}$ and a high level of O-linked oligosaccharides [16]. BSM is the major constituent of mucus in various parts of body and covers the surfaces of the buccal cavity and epithelial organs.

2.5. QCM Measurements. QCM measurements (Affinix QN $\mu$; Initium Co., Ltd., Tokyo, Japan) were used to quantify the amount of adsorbed salivary protein (BSA and BSM). The Affinix QN $\mu$ has a $550 \mu \mathrm{L}$ cell equipped with a $27 \mathrm{MHz}$ QCM plate at the bottom of the cell. The diameter of the quartz plate was $8 \mathrm{~mm}$, and the area of the gold-plated quartz was $4.9 \mathrm{~mm}^{2}$. The unit was equipped with a stirrer bar and a temperature controller. The change in frequency was monitored using a universal frequency counter attached to a microcomputer.

The bare, PMMA, and Ti QCM sensors were immersed in $500 \mu \mathrm{L} \mathrm{PBS}$ solution $(0.01 \mathrm{~mol} / \mathrm{L}$ PBS at $\mathrm{pH} 7.4)$. The change in QCM frequency was recorded as a function of time; recording began immediately after the injection of $5 \mu \mathrm{L}(20 \mu \mathrm{g} / \mathrm{mL})$ of BSA and BSM. The solution was stirred to avoid any protein diffusion effects. This stirring did not affect the stability of the frequency or the magnitude of the change in frequency. The frequency shift depends on the adsorbed mass in accordance with the Sauerbrey equation [17]

$$
\Delta F=-\frac{2 F_{0}^{2} \Delta m}{A \sqrt{\rho_{q} \mu_{q}}} .
$$

According to this equation, at $27 \mathrm{MHz}$, a frequency shift of $1 \mathrm{~Hz}$ corresponds to a mass change of approximately $0.62 \mathrm{ng} \mathrm{cm}^{-2}$ (Figure 1). In the Sauerbrey equation, $\Delta F$ is the measured frequency shift $(\mathrm{Hz}), \Delta m$ is the mass change $(\mathrm{g})$, $F_{0}$ is the fundamental frequency of the quartz crystal $(27 \times$ $\left.10^{6} \mathrm{~Hz}\right), A$ is the electrode area $\left(0.049 \mathrm{~cm}^{2}\right), \rho_{q}$ is the density of quartz $\left(2.65 \mathrm{~g} \mathrm{~cm}^{-3}\right)$, and $\mu_{q}$ is the shear modulus of quartz $\left(2.95 \times 10^{11} \mathrm{dyn} \mathrm{cm}^{-2}\right)$. QCM monitoring was performed at $25^{\circ} \mathrm{C}$ and the experiment was performed in triplicate. Data are described as the mean \pm standard deviation. In this analysis, statistical significance was analyzed using one-way analysis of variance followed by Tukey's test. 


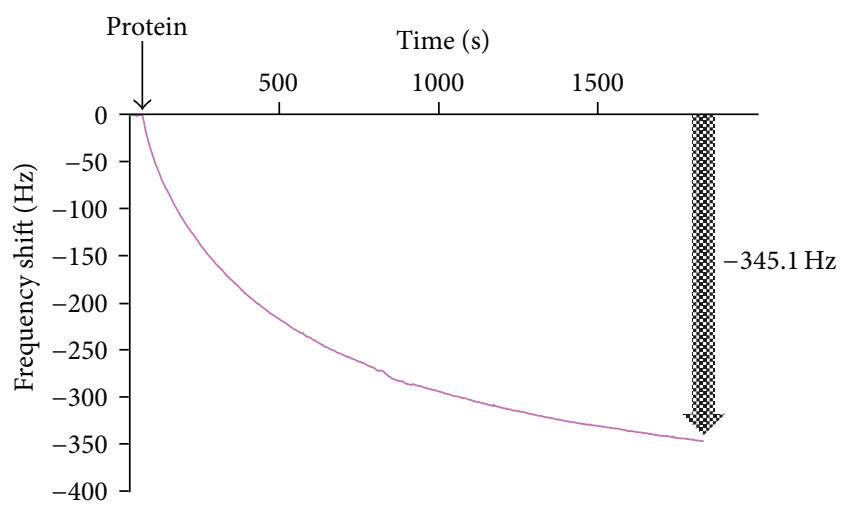

FIGURE 1: Change in frequency of QCM after protein injection. Change in frequency of the quartz crystal microbalance (QCM) after protein injection. In this case, the amount of protein adsorbed is $345.1 \times 0.62=344.48 \mathrm{ng} \mathrm{cm}^{-2}$ onto the QCM sensor.

2.6. XPS Analysis after Adsorption Measurement of Bovine Salivary Proteins, BSA and BSM, Using Control, PMMA, and Ti QCM Sensors. The chemical compositions of the adsorbed salivary protein films on the QCM sensors were analyzed by XPS on an AXIS Ultra DLD spectrometer (Kratos Instruments) equipped with a monochromated $\mathrm{Al} K_{\alpha} \mathrm{X}$-ray source $(h v=1486.6 \mathrm{eV})$ operated at $75 \mathrm{~W}$. XPS was used to analyze the proteinaceous carbon (C1s) and nitrogen (N1s) signals resulting from the protein. Quantification of the C1s and N1s signals arising from the peptide bonds of the salivary protein was used as a measure of the relative amount of protein adsorbed onto the various surfaces.

\section{Results and Discussion}

The PMMA QCM sensors were fabricated by spin-coating a thin film of PMMA dissolved in ethyl acetate solution onto Au QCM sensors. Spin-coating from dilute solution is a common method to produce a thin, uniform polymer film on a planar substrate [18]. In general, the fabrication of polymer QCM sensors involves spin-coating the QCM sensors using a dilute solution of polymer. In our previous study, a $1 \mathrm{mg} / \mathrm{mL}$ solution of PMMA in chloroform solution was used to coat the PMMA thin film onto the gold electrode of the quartz crystal; however, some aggregation of PMMA was observed on the surface. The Ti thin film was fabricated by a reactive DC magnetron sputtering technique. Magnetron sputtering is one of the most widely used methods, which can be optimized to obtain thin films with desired properties. Magnetron sputtering has become important because it enables control of the structure, composition, and properties of biomaterial thin films through adjustment of the deposition condition [19]. An ultrathin film was required to coat onto the gold electrode of the quartz crystal owing to the improvement of the QCM sensor sensitivity. The $200 \mathrm{~nm}$ thick film fabricated in our previous study was improved to $50 \mathrm{~nm}$ by changing the discharge power and sputtering time [8].

3.1. SPM Analysis. The surface morphologies of the control, PMMA, and Ti QCM sensors surfaces were investigated over a surface area of $1.0 \times 1.0 \mu \mathrm{m}$ by SPM. Figure 2 shows the roughness values obtained after SPM image analysis. The surface morphology of the gold-plated quartz is shown in Figure 2(a). The SPM images show the relatively homogenous surface with nano-order grain size. SPM observation clearly revealed the change in surface morphology of the PMMA and Ti QCM sensors, as indicated in Figures 2(b) and 2(c). The surface roughness $\left(R_{a}\right)$ values were $1.949,1.793$, and $2.703 \mathrm{~nm}$ for the control, PMMA, and Ti QCM sensors, respectively. The size and morphology of the deposited particles were different among the three materials. In this study, ethyl acetate solution was used as a solvent and the rotational speed and PMMA concentration were changed. As a result, the surface roughness $\left(R_{a}\right)$ value of the PMMA QCM sensors is smaller than that of our fabricated sensors in our previous study and a uniform surface was obtained [11].

3.2. XPS Analysis. The XPS spectra of the control, PMMA, and Ti QCM sensors are shown in Figures 3, 4, and 5, respectively. The control QCM sensors indicated the presence of Au4f, which is characteristic in atomic Au. The binding energies (BEs) of $\mathrm{Au} 4 \mathrm{f}_{7 / 2}$ and $\mathrm{Au} 4 \mathrm{f}_{5 / 2}$ were 84.1 and $87.8 \mathrm{eV}$, respectively. XPS was performed in this study to determine the chemical composition at the surface of the sample. The Au4f XPS spectrum of the control QCM sensors in this study showed similar BEs of $\mathrm{Au}_{4 / 2}(84.0 \mathrm{eV})$ and $\mathrm{Au}_{7 / 2}$ $(87.7 \mathrm{eV})$, which are characteristic of metallic Au $[20,21]$.

The C1s spectrum, which is characteristic in atomic carbon (C), and the O1s spectrum, which is characteristic in atomic oxygen $(\mathrm{O})$, were observed for the PMMA QCM sensors. For the PMMA QCM sensor surfaces examined, the $\mathrm{C} 1 \mathrm{~s}$ envelope was curve-fitted into four components at BEs of $285.0 \mathrm{eV}$ (C-C/C-H), $285.6 \mathrm{eV}$ (C-C-O), $286.7 \mathrm{eV}$ (C$\mathrm{O} / \mathrm{C}-\mathrm{OH})$, and $289.0 \mathrm{eV}(\mathrm{O}=\mathrm{C}-\mathrm{O})$. These results are similar to those previously reported [21-26]. For example, Beamson and Briggs' previous report supports our C1s and O1s XPS spectra of PMMA obtained from the PMMA QCM sensors [26]. The XPS spectra of PMMA thin films coated on the QCM sensors were quite similar to the $\mathrm{BE}$ of the characteristic spectra of the PMMA solution. However, it should be noted that surface composition of polymerized PMMA might be changed. Further study of the polymerized PMMA QCM sensor mimicking the denture is needed. The O1s envelope can be fitted with two peaks at $532.1 \mathrm{eV}$ and $533.8 \mathrm{eV}$, assigned to $\mathrm{O}=\mathrm{C}$ and $\mathrm{O}-\mathrm{C}$, respectively. The $\mathrm{Ti} 2 \mathrm{p}$ spectrum was observed from the core-level spectrum of Ti QCM sensors, which is a characteristic of atomic Ti. Furthermore, in the Ti2 $p$ spectrum of the Ti surface, BEs of the Ti2 $\mathrm{p}_{3 / 2}$ and Ti2 $\mathrm{p}_{1 / 2}$ peaks in $\mathrm{TiO}_{2}$ were $458.8 \mathrm{eV}$ and $464.4 \mathrm{eV}$ and the Ti2 $\mathrm{p}_{3 / 2}$ peak in Ti was at $453.5 \mathrm{eV}$. A previous report supports our Ti2p XPS spectra of $\mathrm{TiO}_{2}$ obtained from the Ti sensors. BEs of the $\mathrm{Ti} 2 \mathrm{p}_{3 / 2}$ and $\mathrm{Ti} 2 \mathrm{p}_{1 / 2}$ peaks in $\mathrm{TiO}_{2}$ are reported as $458.8 \mathrm{eV}$ and $464.3 \mathrm{eV}$ [27]. The $\mathrm{BE}$ of the $\mathrm{Ti} 2 \mathrm{p}_{3 / 2}$ peak in metal $\mathrm{Ti}$ is reported as $454.1 \mathrm{eV}$ [21]. XPS analysis did not detect the $\mathrm{Au}$ and $\mathrm{Si}$ elements of the gold electrode and the quartz crystal, respectively; thus, a thin uniform film might be formed onto the gold electrode of the quartz crystal.

3.3. Contact Angle Measurements. A cross-sectional view of a water droplet on the surface of the control, PMMA, and $\mathrm{Ti}$ 

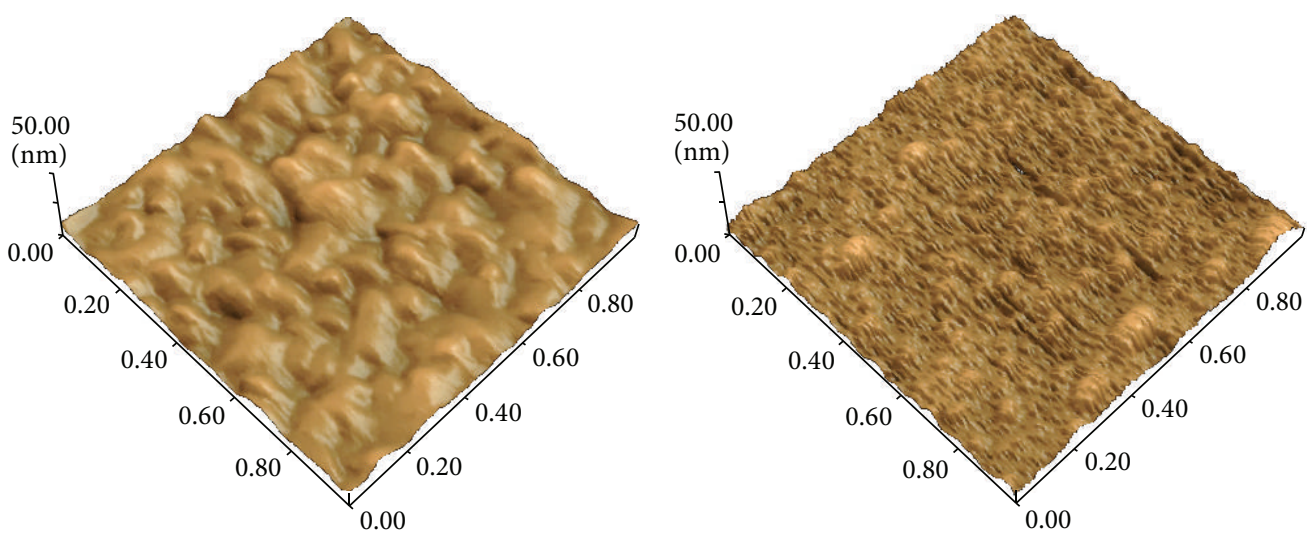

\begin{abstract}
$1000.00 \times 1000.00(\mathrm{~nm}) \quad Z: 0.00-50.00(\mathrm{~nm})$ Bare
\end{abstract}

(a)

\begin{abstract}
$1000.00 \times 1000.00(\mathrm{~nm}) \quad Z: 0.00-50.00(\mathrm{~nm})$
\end{abstract}
(b)

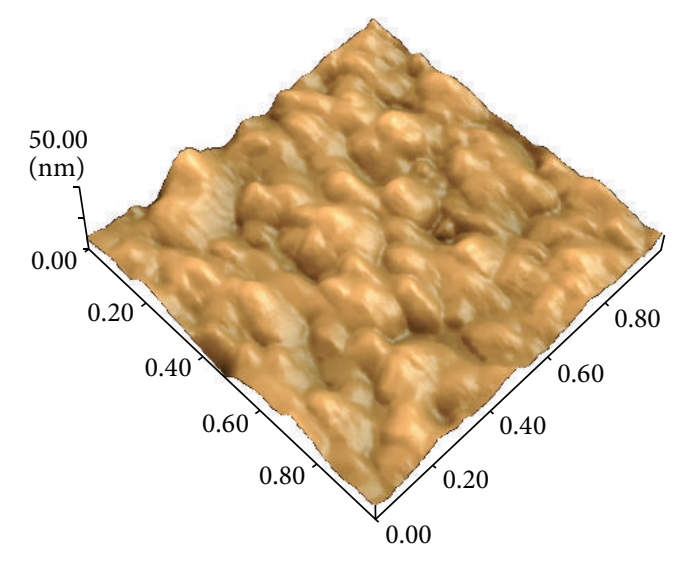

$1000.00 \times 1000.00(\mathrm{~nm}) \quad Z: 0.00-50.00(\mathrm{~nm})$

$\mathrm{Ti}$

(c)

FIGURE 2: Scanning probe microscopy (SPM) images of bare QCM sensor (a), PMMA QCM sensor (b), and Ti QCM sensor (c).

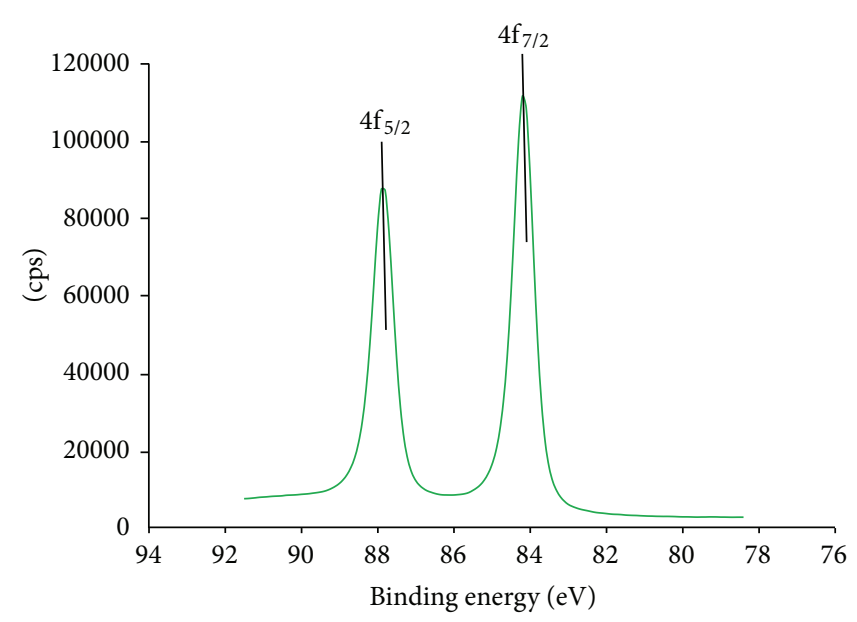

FIGURE 3: XPS analysis of bare (Au) QCM sensor. XPS core-level spectrum of Au4f for the Au (bare) QCM sensor. 


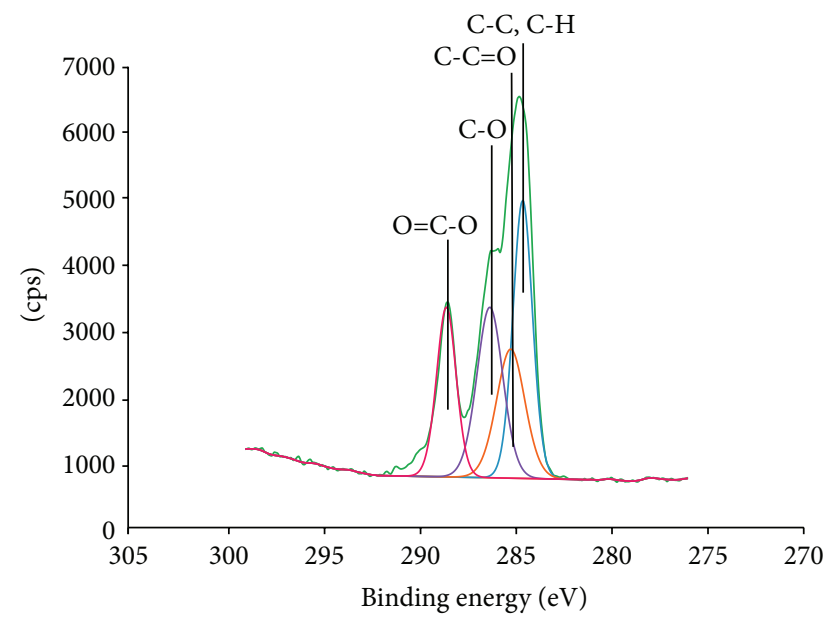

(a)

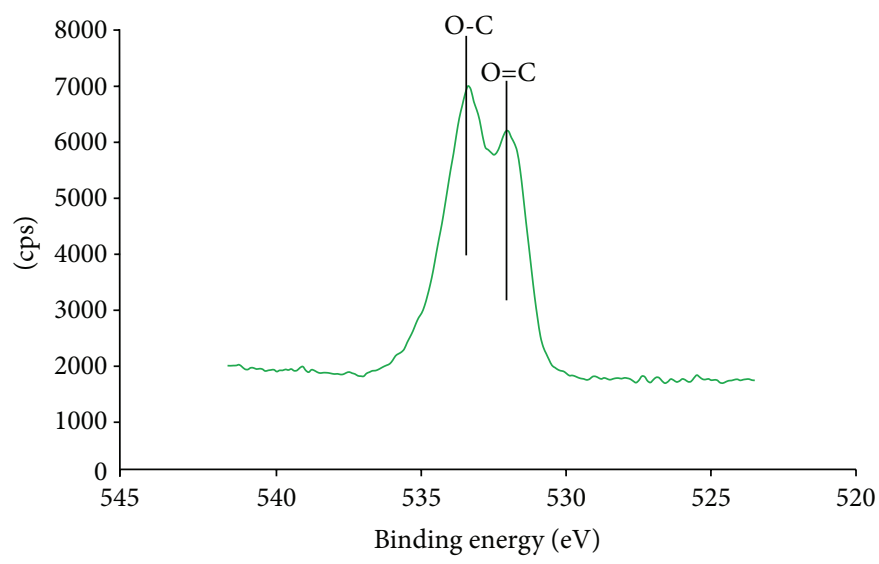

(b)

FIGURE 4: XPS analysis of PMMA QCM sensor. Curve-fitted C1s XPS spectra (a) and core-level XPS spectrum of O1s (b) for a PMMA film.

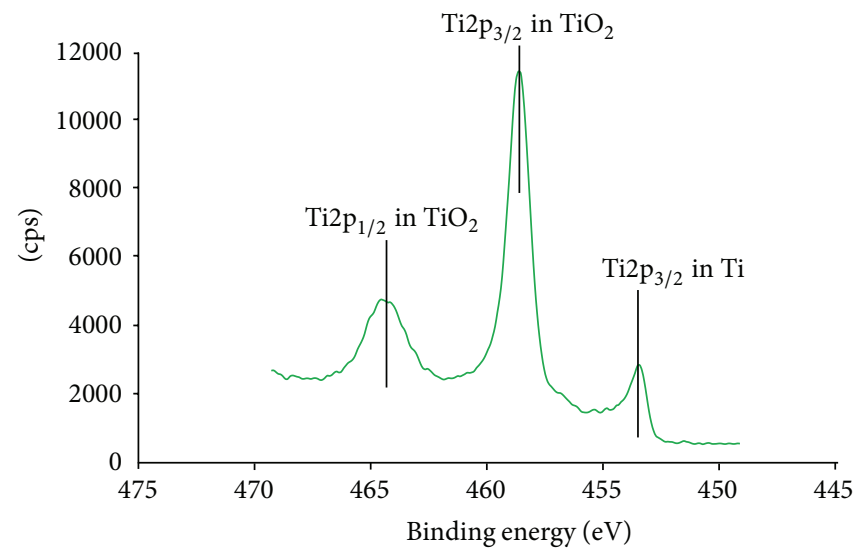

FIGURE 5: XPS analysis of Ti QCM sensor. XPS core-level spectrum of Ti2p for a Ti film.

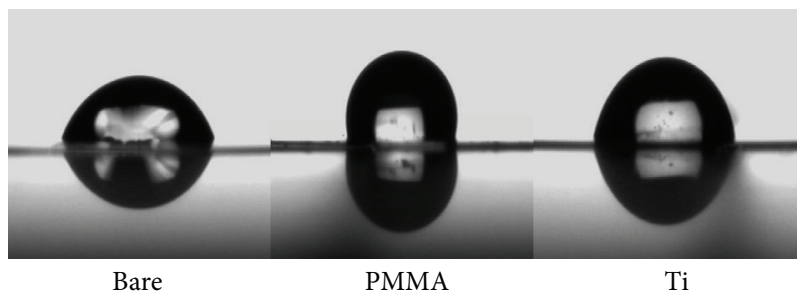

FIGURE 6: Contact angle measurement. Surface wettability of bare, PMMA, and Ti QCM sensors.

QCM sensors and their contact angles are shown in Figure 6. It was found for the contact angles, which were $66.5 \pm 3.3^{\circ}$, $101.7 \pm 1.4^{\circ}$, and $74.5 \pm 2.7^{\circ}$ for the control, PMMA, and $\mathrm{Ti}$ QCM sensors, respectively. Several methods can be used to directly detect and quantify protein adsorption on a biomaterial [28-30]. A QCM is a highly sensitive and practical device for in situ monitoring of protein adsorption. The amount of adsorption of BSA and BSM on the PMMA QCM sensors was higher than those achieved on the Ti and Au QCM sensors. The wettability of a material surface is an important factor for the adsorption of proteins, as determined by the protein adsorption principle. The water contact angle is a standard method for assessing the wettability of a material. The contact angle of PMMA was $101.7^{\circ}$, which shows that the PMMA surface is hydrophobic. However, the contact angle of PMMA was higher than those observed for the Ti and $\mathrm{Au}$ QCM sensors. It has been suggested that biomaterials with hydrophobic surfaces tend to adsorb proteins [1] and the high adsorption for PMMA might be related to the wettability of the material. Further studies are required to investigate the interactions between the QCM film sensors and protein, such as the surface potential and the protein function.

3.4. Adsorption Measurement of Bovine Salivary Proteins, BSA and BSM, Using Control, PMMA, and Ti QCM Sensors. The changes in frequency of the control, PMMA, and Ti QCM sensors on immersion into $2 \mathrm{mg} / \mathrm{mL}$ BSA and BSM solutions are shown in Figure 7. An immediate frequency decrease was observed after the injection of bovine salivary proteins. This 

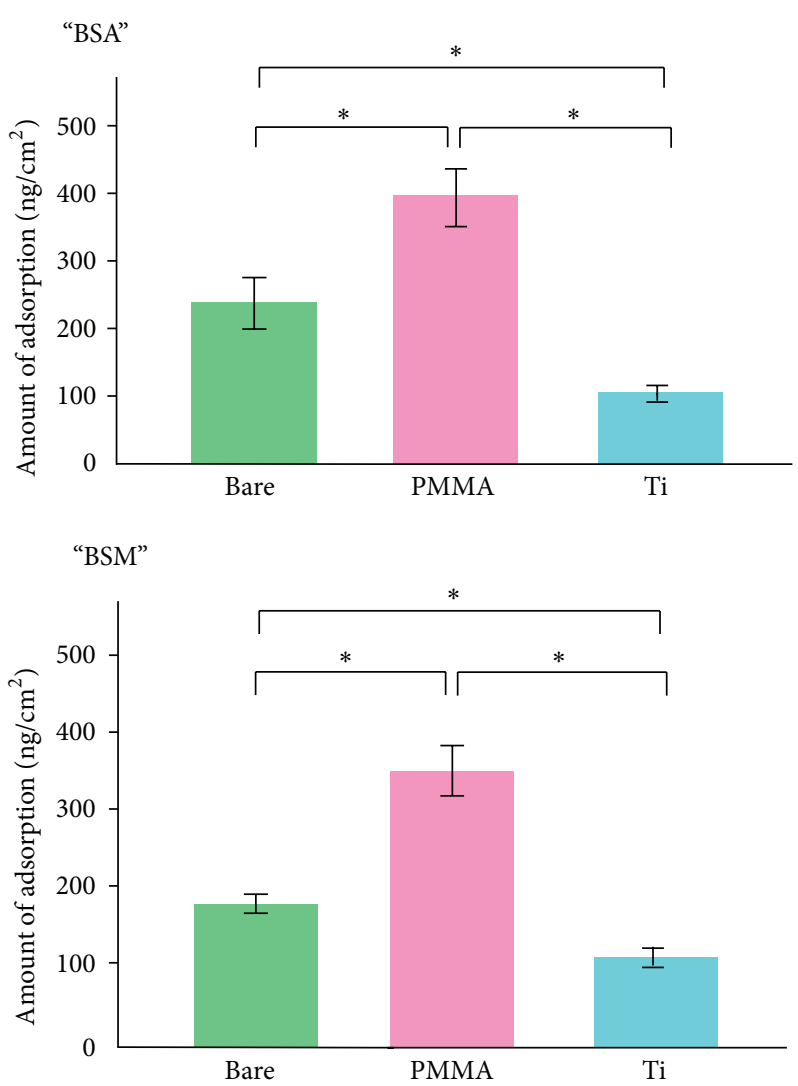

FIGURE 7: QCM measurements for estimating adsorbed amounts of BSA and BSM to bare, PMMA, and Ti QCM sensors. Data are mean \pm $\mathrm{SD}, n=3 . *$ denotes a statistically significant difference $(p<0.05)$.

decrease in frequency was related to the adsorption of bovine salivary proteins. In each case, adsorption is essentially completed within $30 \mathrm{~min}$. The frequency shifts of the control, PMMA, and Ti QCM sensors with BSA were $644.1 \mathrm{~Hz}$, $395.1 \mathrm{~Hz}$, and $160.2 \mathrm{~Hz}$, respectively. Therefore, according to the Sauerbrey equation, the amount of BSA adsorption was $399.3 \mathrm{ng} \mathrm{cm}^{-2}, 250.0 \mathrm{ng} \mathrm{cm}^{-2}$, and $99.3 \mathrm{ng} \mathrm{cm}^{-2}$, respectively. The frequency shifts of the control, PMMA, and Ti QCM sensors with BSM were $545.8 \mathrm{~Hz}, 294.1 \mathrm{~Hz}$, and $190.3 \mathrm{~Hz}$, respectively. According to Sauerbrey equation, the amount of BSM adsorption was $338.4 \mathrm{ng} \mathrm{cm}^{-2}, 182.3 \mathrm{ng} \mathrm{cm}^{-2}$, and $118.0 \mathrm{ng} \mathrm{cm}^{-2}$. The amounts of adsorption of BSA and BSM on the PMMA QCM sensors were the highest when compared with the other QCM sensors. Bacterial adhesion can be mediated by interaction with preadsorbed adhesive proteins but may also be affected, resulting in a greater risk of denture materials-related infections. A QCM is a highly sensitive and practical device for in situ monitoring of protein adsorption. In the present study, we fabricated the QCM sensors with denture materials to investigate the adsorption of salivaryrelated proteins on the denture surface.

3.5. XPS Analysis after Adsorption of Bovine Salivary Proteins. The XPS spectra of control, PMMA, and Ti QCM sensors after immersion in BSA are shown in Figures 8 and 9, and the three QCM sensors after immersion in BSM are shown in Figures 10 and 11. For XPS characterization, the C1s and N1s spectra were recorded. BEs of the $\mathrm{Cls}$ spectrum for adsorbed BSA were $285.0 \mathrm{eV}(\mathrm{C}-\mathrm{C} / \mathrm{C}-\mathrm{H}), 285.9 \mathrm{eV}(\mathrm{C}-\mathrm{O} / \mathrm{C}-\mathrm{N})$, and $288.3 \mathrm{eV}(\mathrm{O}=\mathrm{C}-\mathrm{O})$ for the control QCM sensors, $285.0 \mathrm{eV}$ (C-C/C-H), $285.9 \mathrm{eV}(\mathrm{C}-\mathrm{O} / \mathrm{C}-\mathrm{N})$, and $288.0 \mathrm{eV}(\mathrm{O}=\mathrm{C}-\mathrm{O})$ for the PMMA QCM sensors, and $285.0 \mathrm{eV}(\mathrm{C}-\mathrm{C} / \mathrm{C}-\mathrm{H}), 286.4 \mathrm{eV}$ (C-O/C-N), and 288.6 eV (O=C-O) for the Ti QCM sensors. There was an N1s peak for each of the three QCM sensors after adsorption of BSA. BEs of the C1s spectrum for adsorbed BSM were $285.0 \mathrm{eV}(\mathrm{C}-\mathrm{C} / \mathrm{C}-\mathrm{H}), 286.1 \mathrm{eV}(\mathrm{C}-\mathrm{O} / \mathrm{C}-\mathrm{N})$, and $288.0 \mathrm{eV}(\mathrm{O}=\mathrm{C}-\mathrm{O})$ in the control QCM sensors, $285.0 \mathrm{eV}$ (C-C/C-H), $286.0 \mathrm{eV}(\mathrm{C}-\mathrm{O} / \mathrm{C}-\mathrm{N})$, and $287.5 \mathrm{eV}(\mathrm{O}=\mathrm{C}-\mathrm{O})$ in the PMMA QCM sensors, and $285.0 \mathrm{eV}(\mathrm{C}-\mathrm{C} / \mathrm{C}-\mathrm{H}), 286.1 \mathrm{eV}$ $(\mathrm{C}-\mathrm{O} / \mathrm{C}-\mathrm{N})$, and $288.0 \mathrm{eV}(\mathrm{O}=\mathrm{C}-\mathrm{O})$ in the Ti QCM sensors. After adsorption of the BSM, there were also N1s corelevel spectra for the three QCM sensors. The structure and formation process of denture plaque is known to be the same as that for dental plaque and is composed of proteins and polysaccharides [27]. Endo et al. [31] demonstrated that C, O, and $\mathrm{N}$ derived from the organic material or metal oxide on the Au-In alloy surface were detected by XPS analysis. In this study, C1s and N1s spectra of the QCM sensor surface with adsorbed BSA and BSM were analyzed by XPS, and the C1s and N1s peaks derived from the BSA and BSM were detected 

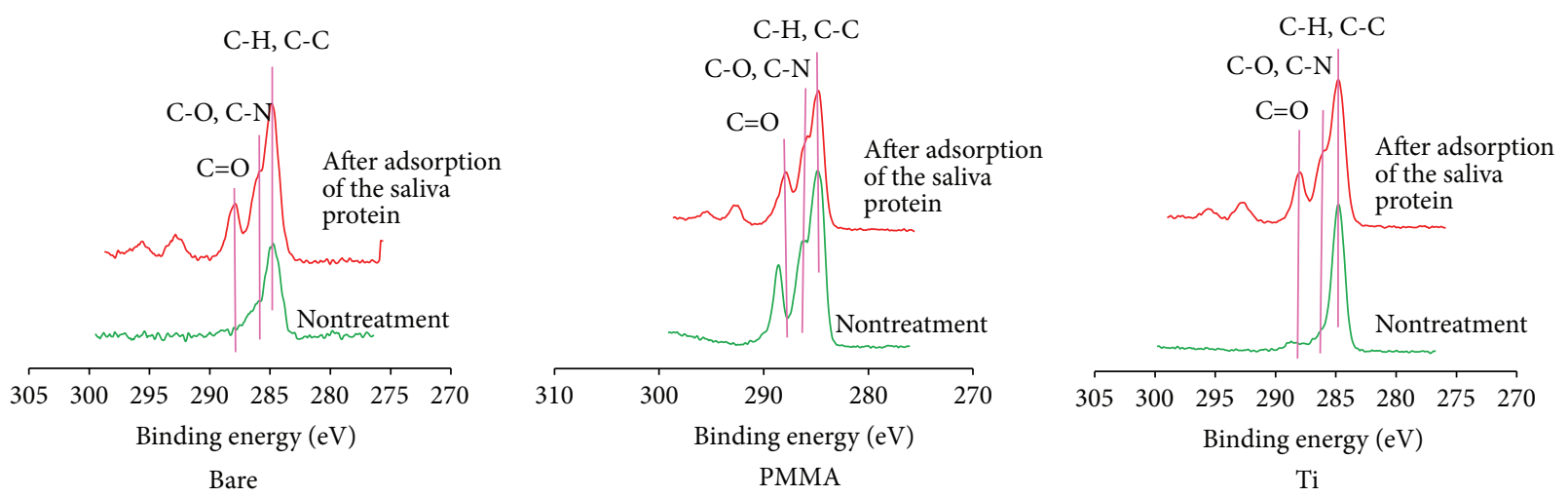

FIGURE 8: XPS analysis after adsorption of BSA. C1s XPS spectra for BSA adsorbed onto bare, PMMA, and Ti QCM sensors. C1s XPS spectra before (green) and after (red) adsorption for BSA.
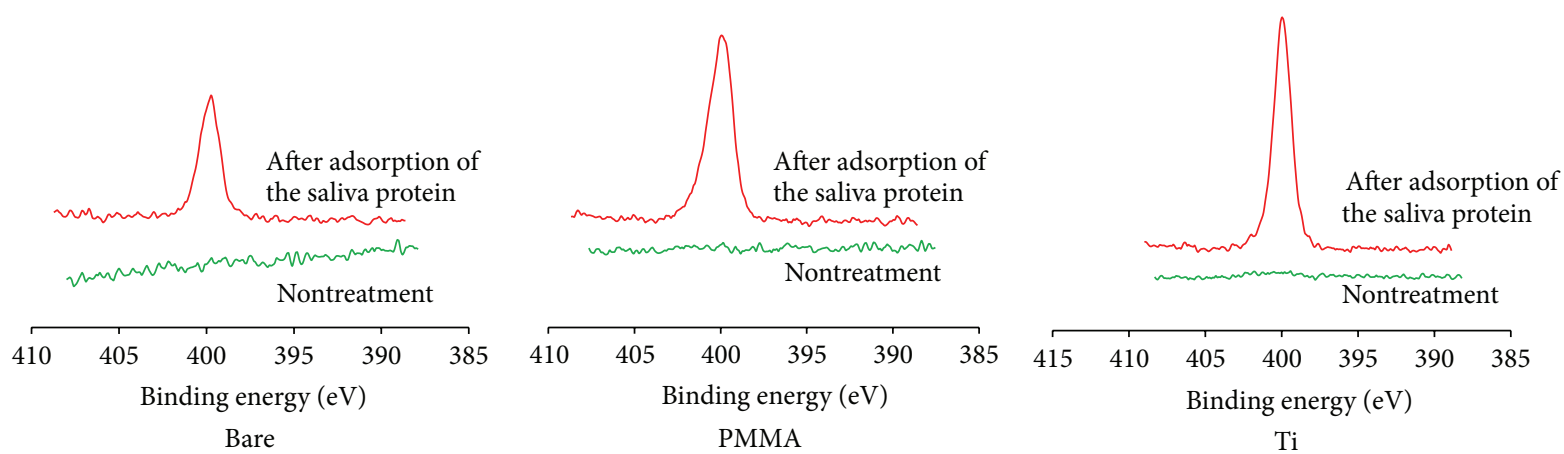

FIGURE 9: XPS analysis after adsorption of BSA. N1s XPS spectra for BSA adsorbed onto bare, PMMA, and Ti QCM sensors. N1s XPS spectra before (green) and after adsorption (red) for BSA.

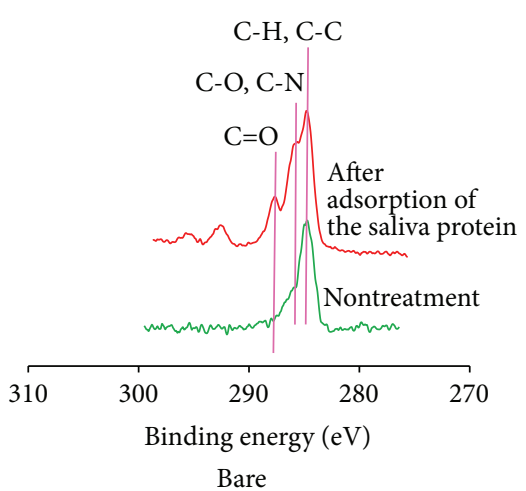

Bare

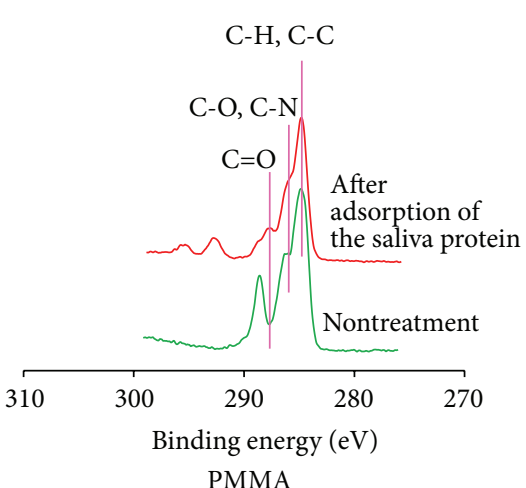

PMMA

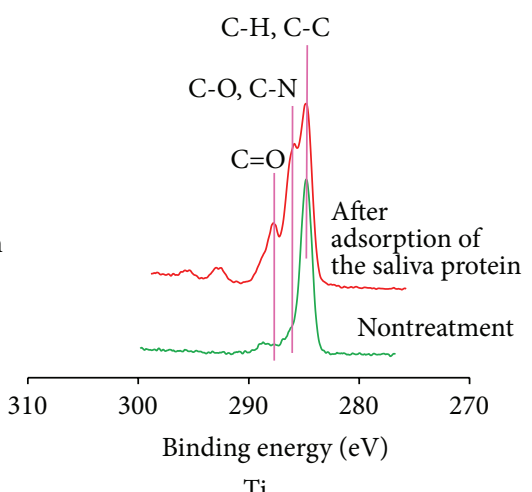

$\mathrm{Ti}$

FIGURE 10: XPS analysis after adsorption of BSM. C1s XPS spectra for BSM adsorbed onto bare, PMMA, and Ti QCM sensors. C1s XPS spectra before (green) and after (red) adsorption for BSM.

on all QCM sensor surfaces tested. The quantification of the N1s peak arising from the peptide bonds of the salivary protein might be effective as a measure of the relative amount of protein adsorbed onto various surfaces.

\section{Conclusion}

We have fabricated highly stable denture material QCM sensors by spin-coating and magnetron sputtering methods. The SPM images show the relatively homogeneous surface with nano-order roughness. The XPS survey spectra of the thin films coated on the QCM sensors were quite similar to the BE observed from the characteristic spectra of the PMMA and Ti. Additionally, the amount of salivary-related protein on the PMMA QCM sensor was higher than those of Ti and $\mathrm{Au}$ QCM sensors and the differences of protein adsorption might be related to the wettability of each material. Our results support that the polymer denture surface exerts strong adhesion of microorganisms. In our pilot study, the addition of sodium dodecyl sulfate, which is an anionic, denaturating 

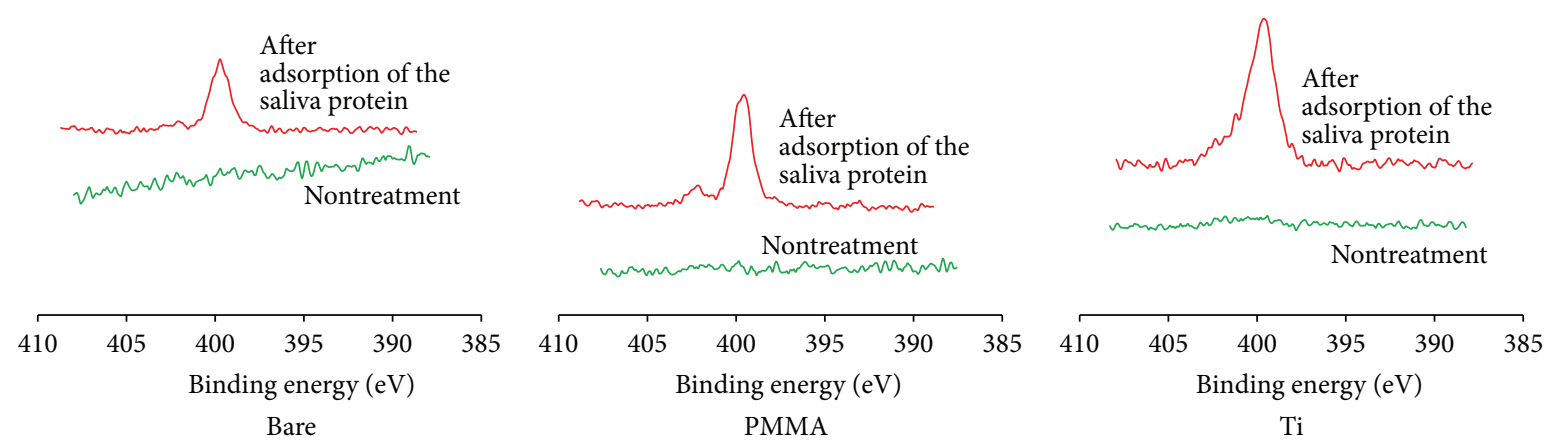

FIGURE 11: XPS analysis after adsorption of BSM. N1s XPS spectra for BSM adsorbed onto bare, PMMA, and Ti QCM sensors. N1s XPS spectra before (green) and after (red) adsorption for BSM.

surfactant, increased the frequency shift of the PMMA/BSA QCM sensor. Further study will be required to investigate the removal of salivary-related protein using a chemical denture cleaner by real-time studies of the QCM.

\section{Conflict of Interests}

The authors declare that there is no conflict of interests regarding the publication of this paper.

\section{Acknowledgments}

This study was partly supported by a Research Promotion Grant (15-05) from Osaka Dental University and a Grantin-Aid for Scientific Research (26462943) from the Japan Society for the Promotion of Science. The authors thank Professor Koichi Imai and Mr. Hideaki Hori from the Central Institute of Dental Research, Osaka Dental University, Japan, and Mr. Yasuyuki Kobayashi from Osaka Municipal Technical Research Institute, Japan, for their encouragement and helpful suggestions. They thank Mr. Yasuyuki Nakanishi from OIKE \& Co., Ltd., Japan, for help in the fabrication of the Ti QCM sensors. They are also grateful to the members of the Department of Removable Prosthodontics and Occlusion, Department of Biomaterials, and Department of Geriatric Dentistry for their kind advice and assistance.

\section{References}

[1] H. Schweikl, K.-A. Hiller, U. Carl et al., "Salivary protein adsorption and Streptococccus gordonii adhesion to dental material surfaces," Dental Materials, vol. 29, no. 10, pp. 1080-1089, 2013.

[2] V. Payet, S. Brunner, A. Galtayries, I. Frateur, and P. Marcus, "Cleaning of albumin-contaminated Ti and Cr surfaces: an XPS and QCM study," Surface and Interface Analysis, vol. 40, no. 3-4, pp. 215-219, 2008.

[3] D. C. Jagger and A. Harrison, "Denture cleansing-the best approach," British Dental Journal, vol. 178, no. 11, pp. 413-417, 1995.

[4] T. Nezu, T. Masuyama, K. Sasaki, S. Saitoh, M. Taira, and Y. Araki, "Effect of $\mathrm{pH}$ and addition of salt on the adsorption behavior of lysozyme on gold, silica, and titania surfaces observed by quartz crystal microbalance with dissipation monitoring," Dental Materials Journal, vol. 27, no. 4, pp. 573-580, 2008.

[5] H. Furusawa, Y. Kitamura, N. Hagiwara, T. Tsurimoto, and Y. Okahata, "Binding kinetics of the toroid-shaped PCNA to DNA strands on a $27 \mathrm{MHz}$ quartz crystal microbalance," ChemPhysChem, vol. 3, no. 5, pp. 446-448, 2002.

[6] Y. Okahata, Y. Matsunobu, K. Ijiro, M. Mukae, A. Murakami, and K. Makino, "Hybridization of nucleic acids immobilized on a quartz crystal microbalance," Journal of the American Chemical Society, vol. 114, no. 21, pp. 8299-8300, 1992.

[7] Y. Hashimoto, S. Minoura, A. Nishiura, R. Honda, N. Matsumoto, and S. Takeda, "Development of titanium quartz microbalance sensor by magnetron sputtering," Journal of Oral Tissue Engineering, vol. 8, pp. 52-59, 2010.

[8] S. Minoura, Y. Hashimoto, A. Nishiura, R. Honda, and N. Matsumoto, "Adsorption of salivary-related proteins on the surface of orthodontic materials evaluated using quartz crystal microbalance," Nano Biomedicine, vol. 2, no. 2, pp. 114-122, 2010.

[9] M. Tagaya, T. Ikoma, T. Takemura et al., "Adsorption of proteins derived from fetal bovine serum onto hydroxyapatite nanocrystals with quartz crystal microbalance technique," Key Engineering Materials, vol. 396-398, pp. 47-50, 2009.

[10] A. Monkawa, T. Ikoma, S. Yunoki et al., "Fabrication of hydroxyapatite ultra-thin layer on gold surface and its application for quartz crystal microbalance technique," Biomaterials, vol. 27, no. 33, pp. 5748-5754, 2006.

[11] A. Miyake, S. Komasa, Y. Hashimoto et al., "Fabrication of PMMA QCM sensor," The Journal of Japan Association of Oral Rehabilitation, vol. 26, pp. 22-29, 2013.

[12] R. G. Jagger, M. S. Al-Athel, and R. W. Jagger, "Some variables influencing the bond strength between PMMA and a silicone denture lining material," The International Journal of Prosthodontics, vol. 15, no. 1, pp. 55-58, 2001.

[13] C. J. Thomas, S. Lechner, and T. Mori, "Titanium for removable dentures. II. Two-year clinical observations," Journal of Oral Rehabilitation, vol. 24, no. 6, pp. 414-418, 1997.

[14] P. A. Hansen and L. A. West, "Allergic reaction following insertion of a Pd-Cu-Au fixed partial denture: a clinical report," Journal of Prosthodontics, vol. 6, no. 2, pp. 144-148, 1997.

[15] D. T. H. Wassell and G. Embery, "Adsorption of bovine serum albumin on to titanium powder," Biomaterials, vol. 17, no. 9, pp. 859-864, 1996. 
[16] J. A. Lori and A. J. Nok, "Mechanism of adsorption of mucin to titanium in vitro," Bio-Medical Materials and Engineering, vol. 14, no. 4, pp. 557-563, 2004.

[17] G. Sauerbrey, The Use of Quartz Crystal Oscillators for Weighing Thin Layers and for Microweighing Applications, 1959.

[18] D. B. Hall, P. Underhill, and J. M. Torkelson, "Spin coating of thin and ultrathin polymer films," Polymer Engineering and Science, vol. 38, no. 12, pp. 2039-2045, 1998.

[19] M. Yamagishi, S. Kuriki, P. K. Song, and Y. Shigesato, “Thin film $\mathrm{TiO}_{2}$ photocatalyst deposited by reactive magnetron sputtering," Thin Solid Films, vol. 442, no. 1-2, pp. 227-231, 2003.

[20] R. Leppelt, B. Schumacher, V. Plzak, M. Kinne, and R. J. Behm, "Kinetics and mechanism of the low-temperature water-gas shift reaction on $\mathrm{Au} / \mathrm{CeO}_{2}$ catalysts in an idealized reaction atmosphere," Journal of Catalysis, vol. 244, no. 2, pp. 137-152, 2006.

[21] J. Moulder, W. Stickle, P. Sobol, and K. Bomben, Handbook of X-Ray Photoelectron Spectroscopy: A Reference Book of Standard Spectra for Identification and Interpretation of XPS Data, Physical Electronics, 1995.

[22] N. Zammarelli, M. Luksin, H. Raschke, R. Hergenröder, and R. Weberskirch, "'Grafting-from' polymerization of PMMA from stainless steel surfaces by a RAFT-mediated polymerization process," Langmuir, vol. 29, no. 41, pp. 12834-12843, 2013.

[23] R. A. D’Sa, G. A. Burke, and B. J. Meenan, "Protein adhesion and cell response on atmospheric pressure dielectric barrier discharge-modified polymer surfaces," Acta Biomaterialia, vol. 6, no. 7, pp. 2609-2620, 2010.

[24] R. A. D'Sa and B. J. Meenan, “Chemical grafting of poly(ethylene glycol) methyl ether methacrylate onto polymer surfaces by atmospheric pressure plasma processing," Langmuir, vol. 26, no. 3, pp. 1894-1903, 2010.

[25] M. Yoshinari, T. Kato, K. Matsuzaka et al., "Adsorption behavior of antimicrobial peptide histatin 5 on PMMA," Journal of Biomedical Materials Research Part B: Applied Biomaterials, vol. 77, no. 1, pp. 47-54, 2006.

[26] G. Beamson and D. Briggs, "High resolution XPS of organic polymers," 1992.

[27] Z.-F. Cai, H.-J. Dai, S.-H. Si, and F.-L. Ren, "Molecular imprinting and adsorption of metallothionein on nanocrystalline titania membranes," Applied Surface Science, vol. 254, no. 15, pp. 4457-4461, 2008.

[28] D. R. Radford, S. J. Challacombe, and J. D. Walter, "Denture plaque and adherence of Candida albicans to denture-base materials in vivo and in vitro," Critical Reviews in Oral Biology and Medicine, vol. 10, no. 1, pp. 99-116, 1999.

[29] H. Nikawa, S. Hayashi, Y. Nikawa, T. Hamada, and L. P. Samaranayake, "Interactions between denture lining material, protein pellicles and Candida albicans," Archives of Oral Biology, vol. 38, no. 7, pp. 631-634, 1993.

[30] H. Nikawa, H. Iwanaga, M. Kameda, and T. Hamada, "In vitro evaluation of Candida albicans adherence to soft denture-lining materials," The Journal of Prosthetic Dentistry, vol. 68, no. 5, pp. 804-808, 1992.

[31] K. Endo, Y. Araki, H. Ohno, and K. Matsuda, "ESCA analysis of tarnish films on dental alloys removed from the oral cavities (part 1) Ag-In alloys," Journal of the Japanese Society for Dental Materials and Devices, vol. 7, no. 2, pp. 184-191, 1988. 

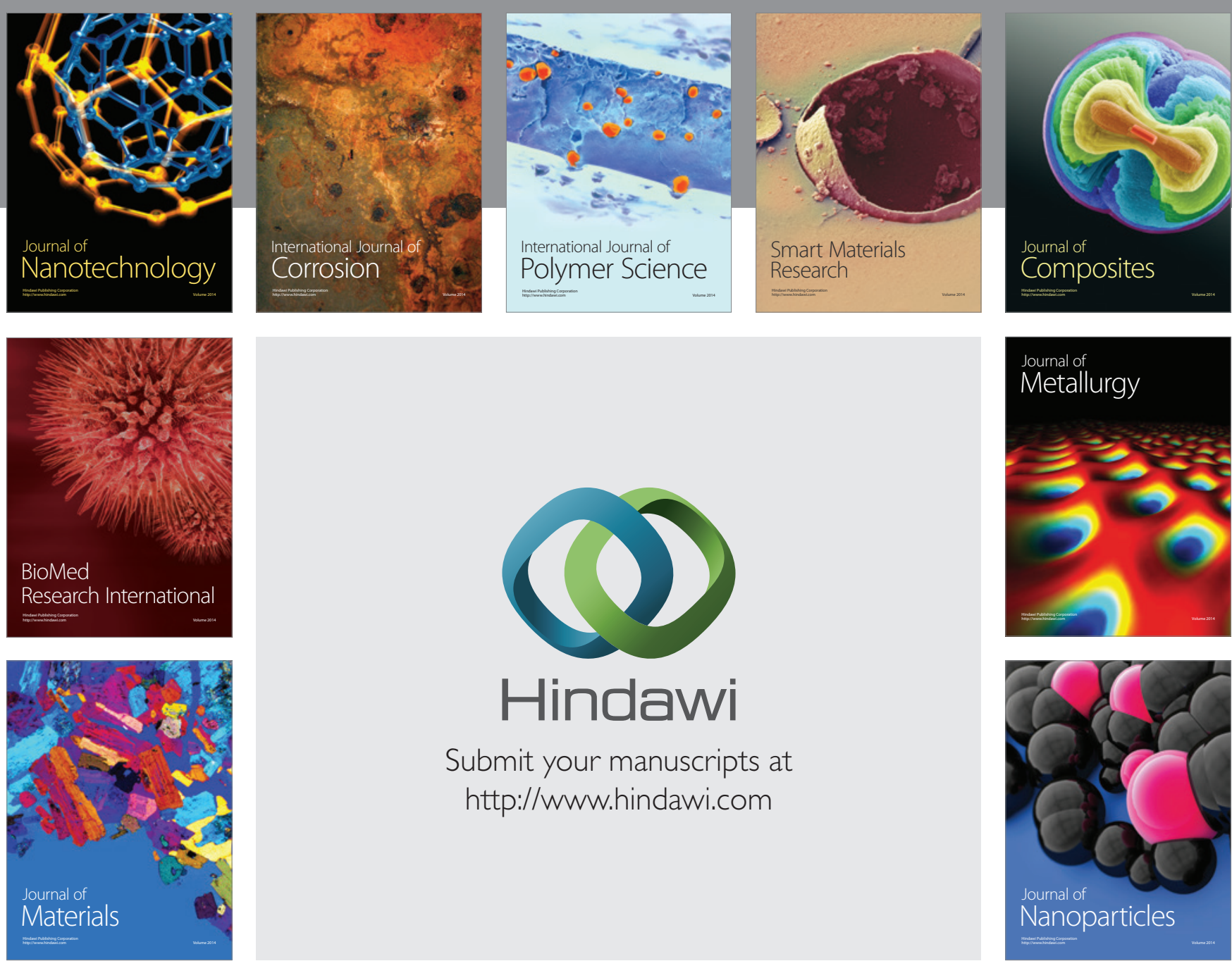

\section{Hindawi}

Submit your manuscripts at

http://www.hindawi.com

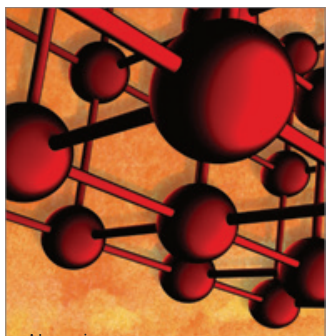

Materials Science and Engineering
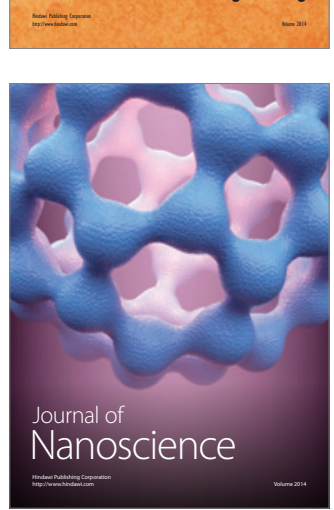
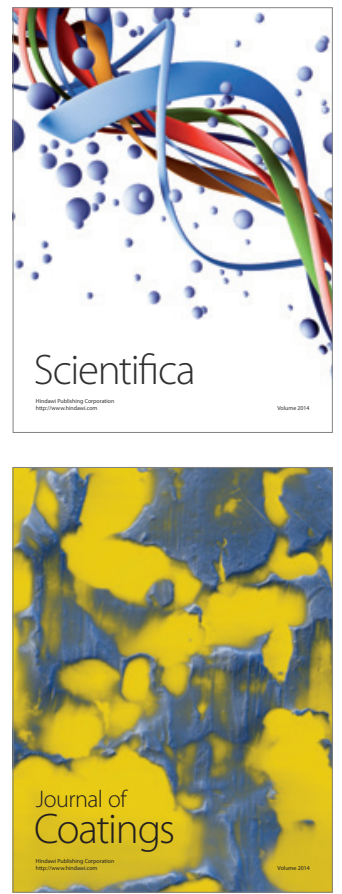
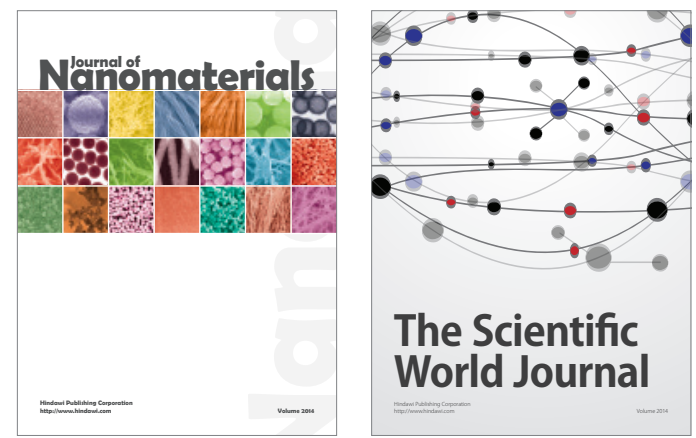

The Scientific World Journal
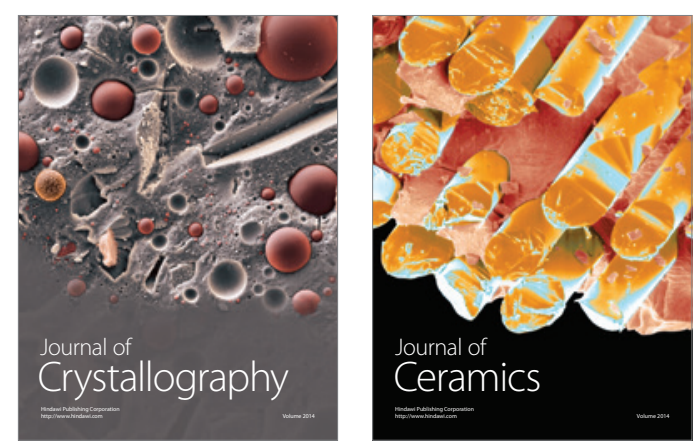
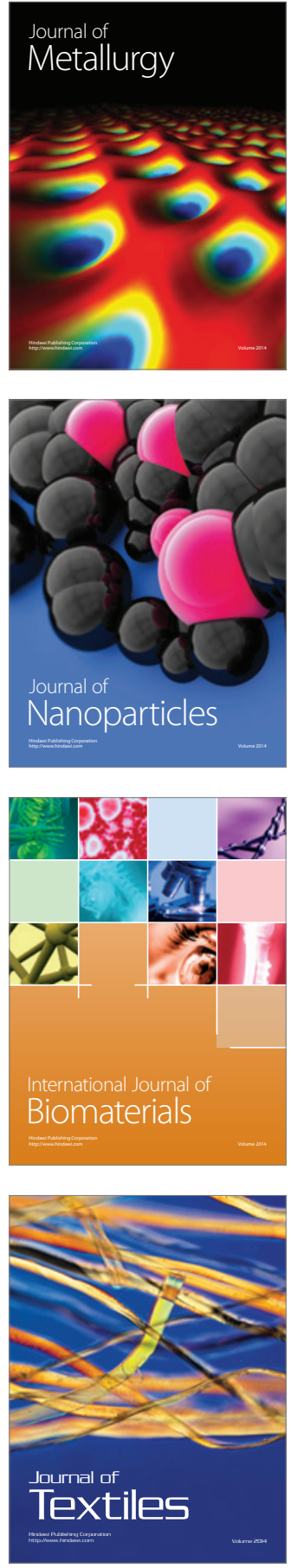